\title{
BMJ Open Glycaemic control in type 2 diabetes patients and its predictors: a retrospective database study at a tertiary care diabetes centre in Ningbo, China
}

\author{
Jialin Li, ${ }^{1}$ Kaushik Chattopadhyay, ${ }^{2}$ Miao Xu, ${ }^{1}$ Yanshu Chen, ${ }^{1}$ Fangfang Hu, ${ }^{1}$ \\ Jianping Chu, ${ }^{1} \mathrm{Li} \mathrm{Li}^{1}$
}

To cite: Li J, Chattopadhyay K Xu M, et al. Glycaemic control in type 2 diabetes patients and its predictors: a retrospective database study at a tertiary care diabetes centre in Ningbo, China. BMJ Open 2018;8:e019697. doi:10.1136/ bmjopen-2017-019697

\section{- Prepublication history for} this paper is available online. To view these files, please visit the journal online (http://dx.doi org/10.1136/bmjopen-2017019697).

$\mathrm{JL}$ and $\mathrm{KC}$ are co-first authors

Received 19 September 2017 Revised 2 February 2018 Accepted 6 March 2018
Check for updates

${ }^{1}$ Department of Endocrinology and Metabolism, Ningbo First Hospital, Ningbo, China ${ }^{2}$ Division of Epidemiology and Public Health, School of Medicine, University of Nottingham, Nottingham, UK

Correspondence to Dr Li Li; lilyningbo@163.com

\section{ABSTRACT}

Objectives The objectives of the study were to assess glycaemic control in patients with type 2 diabetes (T2DM) at a tertiary care diabetes centre in Ningbo, China and to determine factors that independently predict their glycaemic control.

Design Retrospective cross-sectional study using an existing database, the Diabetes Information Management System.

Setting Tertiary care diabetes centre in Ningbo, China. Participants The study included adult patients with T2DM, registered and received treatment at the diabetes centre for at least six consecutive months. The study inclusion criteria were satisfied by 1387 patients, from 1 July 2012 to 30 June 2017.

Primary outcome measure Glycaemic control (poor was defined as glycated haemoglobin $(\mathrm{HbA1c})>=7 \%$ or fasting blood glucose (FBG)>7.0 mmol/L).

Results In terms of $\mathrm{HbA} 1 \mathrm{c}$ and $\mathrm{FBG}$, the 5 -year period prevalence of poor glycaemic control was $50.3 \%$ and $57.3 \%$, respectively. In terms of $\mathrm{HbA} 1 \mathrm{c}$ and FBG, the odds of poor glycaemic control increased with the duration of T2DM (>1 to 2 years: $0 R$ 1.84, $95 \% \mathrm{Cl} 1.06$ to 3.19 ; $>2$ to 4 years: $3.32,1.88$ to 5.85 and $>4$ years: $5.98,4.09$ to 8.75 and $>1$ to 2 years: $2.10,1.22$ to $3.62 ;>2$ to 4 years: $2.48,1.42$ to 4.34 and $>4$ years: $3.34,2.32$ to 4.80 ) and were higher in patients residing in rural areas $(1.68,1.24$ to 2.28 and $1.42,1.06$ to 1.91 ), with hyperlipidaemia $(1.57,1.12$ to 2.19 and $1.68,1.21$ to 2.33$)$, on diet, physical activity and oral hypoglycaemic drug (OHD) as part of their T2DM therapeutic regimen (1.80, 1.01 to 3.23 and $2.40,1.36$ to 4.26 ) and on diet, physical activity, OHD and insulin $(2.47,1.38$ to 4.41 and $2.78,1.58$ to 4.92$)$, respectively.

Conclusions More than half of patients with T2DM at the diabetes centre in Ningbo, China have poor glycaemic control, and the predictors of glycaemic control were identified. The study findings could be taken into consideration in future interventional studies aimed at improving glycaemic control in these patients.

\section{INTRODUCTION}

China has the world's largest type 2 diabetes (T2DM) epidemic, a complex metabolic disorder which has major health, social and

\section{Strengths and limitations of this study}

- This is the first study to explore glycaemic control in patients with type 2 diabetes at the tertiary care diabetes centre in Ningbo, China and as far as we are aware, in the Zhejiang province of China.

- Glycated haemoglobin (which reflects the average blood glucose level over the past 3 months) and fasting blood glucose (a short-term index) were used to determine glycaemic control, which in turn provided a complete picture.

- Missing data could lead to bias but were generally low in this study. Multiple regression analyses included a sample with missing values for the adjusted variables.

- This retrospective study was conducted using an existing database, which is primarily developed for the clinical purpose and not for research (ie, issues with routinely collected data were present).

- As this was a cross-sectional study, it was not possible to determine the causal association between different variables and glycaemic control.

economic consequences. Almost $11 \%$ of all adults are currently living with T2DM (around 114 million). This number is expected to increase to around 150 million by $2040 .{ }^{1}$ Its chronic hyperglycaemia is associated with long-term complications (eg, cardiovascular disease) and even death. ${ }^{2}$ In China, T2DM and its complications contribute to almost 1 million deaths each year. Alarmingly, nearly $40 \%$ of these deaths are premature (ie, in people below the age of 70). ${ }^{3}$ China spends upwards of US\$25 billion a year on the management of T2DM and $13 \%$ of its medical expenditures are directly caused by T2DM. ${ }^{4}$ In spite of this, many patients with T2DM have poor glycaemic control $(51 \%-$ $68 \%){ }^{5-9}$ Unfortunately, these figures are much higher as compared with many developed countries. ${ }^{10} 11$ 
In China, hospitals are categorised into three: primary care, secondary care and tertiary care. A primary care hospital (community hospital with general practitioners) usually has less than 100 beds and are mainly responsible for providing preventive care and minimal health services. A secondary care hospital usually has 100 to 500 beds and are mainly responsible for providing health services and for performing a role in medical education and research. A tertiary care hospital usually has more than 500 beds and are mainly responsible for providing specialist health services and for performing a bigger role in medical education and research. ${ }^{12}$ In China, people (including patients with T2DM) can attend any hospital of their choice. In other words, it is not based on any referral system by the community hospital with general practitioners.

Ningbo is one of the most economically developed Chinese cities, located in the northeast Zhejiang province. In 2015, the prevalence of T2DM in people over 40 years of age in the city was around $21 \% .{ }^{13}$ There are 152 community hospitals with general practitioners, 21 secondary hospitals and 21 tertiary care hospitals in the city. Ningbo First Hospital, with 1600 beds, is a tertiary care hospital. Local patients, as well as those from surrounding areas, visit this hospital. ${ }^{14}$ The hospital's diabetes centre has a team of qualified and experienced diabetes experts. Until now, no research has been conducted to explore glycaemic control in patients with T2DM at the diabetes centre. The objectives of the study were to assess their glycaemic control and to determine factors that independently predict their glycaemic control. Knowledge of factors associated with the poor glycaemic control in these patients would provide valuable information about strategies that healthcare professionals and providers can address to improve their glycaemic control.

\section{METHODS}

\section{Study design, data source and period}

A retrospective cross-sectional study was conducted using an existing computerised medical records' database, the Diabetes Information Management System. This database was developed by the Yinal Software Corporation, China for the diabetes centre. The study period was from $1 \mathrm{July}$ 2012 to 30 June 2017 (5 years) and the database included 6699 patients.

\section{Study population, inclusion and exclusion criteria}

The study included adult (18 years of age or older) patients, diagnosed with T2DM and registered and received treatment at the diabetes centre for at least six consecutive months. In China, patients with T2DM are usually given at least 6 months' time to adjust to their T2DM therapeutic regimen and control their blood glucose levels. Those diagnosed with type 1 diabetes, gestational diabetes, secondary diabetes, unknown type of diabetes or endocrine diseases (such as Cushing syndrome and hyperthyroidism which may increase their blood glucose levels) were excluded from the study. The study inclusion criteria were satisfied by 1387 patients.

\section{Study variables}

The following variables (measured after 6 months of treatment at the diabetes centre) were extracted from the database: age: $18-39$ years, $40-59$ years or $\geq 60$ years; sex; education: university/college, class 7 to 12, class 1 to 6 or no qualifications; occupation: manual workers (ie, more physical than mental work), non-manual workers (ie, more mental than physical work) or never worked/ retired; marital status: married or single/divorced/ widowed; residence: urban or rural based on the 'hukou' system (ie, residence registration system in China) ${ }^{15}$; health insurance; smoking (current status); alcohol drinking (current status); family history of T2DM (any parent or sibling); duration of T2DM: $\leq 1$ year, $>1$ to 2 years, $>2$ to 4 years or $>4$ years; number of visits to the diabetes centre for T2DM since registration; T2DM therapeutic regimen: only diet and physical activity, diet and physical activity and oral hypoglycaemic drug ((OHD) metformin, acarbose, sulfonylureas, meglitinides and/or thiazo-lidinediones), diet and physical activity and insulin (long-term insulin, intermediate insulin, rapid-acting insulin and/or premix insulin) or diet and physical activity, OHD and insulin ${ }^{16}$; body mass index (BMI): under $\left(<18.5 \mathrm{~kg} / \mathrm{m}^{2}\right)$, normal $\left(18.5-23.9 \mathrm{~kg} / \mathrm{m}^{2}\right)$, overweight $\left(24.0-27.9 \mathrm{~kg} / \mathrm{m}^{2}\right)$ or obese $\left(\geq 28 \mathrm{~kg} / \mathrm{m}^{2}\right)^{17}$; hypertension (diagnosis based on blood pressure $\geq 140 / 90 \mathrm{~mm} \mathrm{Hg}$ ); hyperlipidaemia (diagnosis based on serum lipids-total cholesterol $\geq 4.5 \mathrm{mmol} / \mathrm{L}$ or triglycerides $\geq 1.7 \mathrm{mmol} / \mathrm{L}$ ) and blood glucose levels. Following the current guideline for the prevention and management of T2DM in China, poor glycaemic control was defined as glycated haemoglobin (HbA1c) $\geq 7 \%$ or fasting blood glucose (FBG) $>7.0 \mathrm{mmol} / \mathrm{L}^{16}$ The HbAlc was estimated using the high-performance liquid chromatographic method, using the D-10 Haemoglobin Analyzer (Bio-Rad, USA). The FBG was estimated using the glucose oxidase method. It should be noted that data on dipeptidyl peptidase-4 (DPP-4) inhibitors and glucagon-like peptide 1 (GLP-1) receptor agonists were not available in the database. These drugs are not covered by the existing health insurance system in China and thus, these drugs are not sold in this hospital. ${ }^{18}$

\section{Ethics}

The study was ethically approved by the Research Ethics Committee at the Ningbo First Hospital, China.

\section{Statistical analyses}

The 5-year period prevalence of poor glycaemic control in patients with T2DM at the diabetes centre was calculated. Simple logistic regression methods were used to investigate the association between glycaemic control and other variables. To identify any independent association, multiple logistic regression models were developed using backward stepwise regression analyses and all the other 
variables were included. Sensitivity analyses were carried out—only those variables with a $p$ value of $\leq 0.20$ in simple logistic regressions were included in multiple logistic regression models. Multiple regression models included a sample with unknown values for these adjusted variables. ORs and their respective $95 \%$ CIs were calculated. The results were considered significant when $p$ values were $\leq 0.05$. All data were analysed using IBM SPSS Statistics V.20.0 for Windows.

\section{RESULTS}

Fifty-seven per cent of patients with T2DM were male and the mean age was 54.1 years. In terms of $\mathrm{HbAlc}$ and FBG, the 5-year period prevalence of poor glycaemic control was $50.3 \%(\mathrm{n}=698)$ and $57.3 \%(\mathrm{n}=791)$, respectively. Table 1 reports the characteristics of patients with T2DM with good and poor glycaemic control. In terms of HbA1c and FBG, glycaemic control was found to be associated with age, education, residence, duration of T2DM and T2DM therapeutic regimen. The additional associated factors were hypertension in the case of HbAlc and alcohol drinking and hyperlipidaemia in the case of FBG.

Table 2 shows the multiple backward stepwise logistic regression analyses to determine factors independently associated with the poor glycaemic control. In terms of both HbAlc and FBG, the odds of poor glycaemic control increased with the duration of T2DM and were higher in patients residing in rural areas, with hyperlipidaemia, on diet, physical activity and OHD as part of their T2DM therapeutic regimen, and on diet, physical activity, OHD and insulin. In addition, in terms of FBG, the odds of poor glycaemic control were lower in patients with hypertension.

Table 3 reports the sensitivity analyses-multiple logistic regression models included only those variables with a $p$ value of $\leq 0.20$ in simple logistic regressions. Similar results were found in the sensitivity analyses except for the association between glycaemic control (in terms of FBG) and hypertension.

\section{DISCUSSION}

In terms of HbAlc and FBG, the 5-year period prevalence of poor glycaemic control in patients with T2DM at the tertiary care diabetes centre in Ningbo, China was $50.3 \%$ and $57.3 \%$, respectively. In other words, less than half of patients with T2DM at the diabetes centre have adequate glycaemic control. The finding is consistent with a recent nationwide population-based study $(51 \%)$ and a recent nationwide hospital-based study $(52 \%) .{ }^{5}$ However, two other recent nationwide hospital-based studies reported much higher figures $(65 \%$ and $68 \%) .{ }^{78}$ These hospital-based studies included a range of hospitals with different tier levels. In terms of glycaemic control in patients with T2DM, tertiary care hospitals usually perform better as compared with primary or secondary care hospitals, ${ }^{19}$ and this could be the case in our study. Another reason could be different population characteristics in these studies. For example, the study which reported $68 \%$ included only those patients with T2DM who were on OHDs alone or in combination with either insulin or GLP-1 receptor agonists, indicating poor glycaemic control with the disease progression. In spite of the availability of diabetes experts at this tertiary care diabetes centre, the prevalence of poor glycaemic control in patients with T2DM was high in our study as compared with other studies conducted in various developed countries. ${ }^{10}{ }^{11}$ Some of the reasons could be non-usage of new hypoglycaemic drugs (such as DPP-4 inhibitors and GLP-1 receptor agonists) and inadequate self-management of T2DM in this population. This indicates that there is still a room for improvement at this diabetes centre. It should be noted that Chinese people are more susceptible to T2DM as compared with Whites (eg, they develop T2DM at a much younger age). ${ }^{20}$ It should also be noted that blood glucose levels of some patients could be relaxed, especially those who are old and frail. However, for the purpose of analysis, the glycaemic control was categorised into poor and good, based on the current guideline for the prevention and management of T2DM in China. ${ }^{16}$

In the unadjusted models (HbAlc and FBG), glycaemic control was found to be associated with age, education, residence, duration of T2DM and T2DM therapeutic regimen. The additional associated factors were hypertension in the case of HbAlc and alcohol drinking and hyperlipidaemia in the case of FBG. Previous studies conducted among patients with T2DM in various countries reported similar and other factors associated with glycaemic control (such as age, sex, education, alcohol drinking, duration of T2DM, T2DM therapeutic regimen, overweight or obese, hypertension and hyperlipidaemia). ${ }^{71921-26}$

The association found between poor glycaemic control and longer duration of T2DM is consistent with previous studies. ${ }^{8}{ }^{211}{ }^{26-28}$ Since T2DM is a progressive disease, the function and mass of $\beta$-cells gradually decline with the disease progression. ${ }^{29}$ To attain glycaemic control, a stepwise approach has been recommended in the national T2DM management guideline. ${ }^{16}$ The first and foremost step should be lifestyle modification (ie, diet and physical activity), followed by addition of $\mathrm{OHD}(\mathrm{s})$ and/or insulin(s) with the disease progression. An association was found between poor glycaemic control and addition of $\mathrm{OHD}(\mathrm{s})$ and insulin(s), and the finding is consistent with previous studies. ${ }^{26} 30$ This relationship more likely represents a marker of T2DM chronicity and severity than of medication effects themselves. Another reason could be the failure of clinicians to intensify therapy in a timely manner. ${ }^{31}{ }^{32}$ The uptake and adherence to the T2DM therapeutic regimen among patients could also be different from what was prescribed. ${ }^{2532}$ A recent study showed that only $43 \%$ of patients with T2DM adhered to their therapeutic regimen (OHD(s) and/or insulin(s)) in China. ${ }^{33}$ In the database, data were available on prescription but not on uptake and adherence. Thus, these issues 
Table 1 Characteristics of patients with T2DM with good and poor glycaemic control

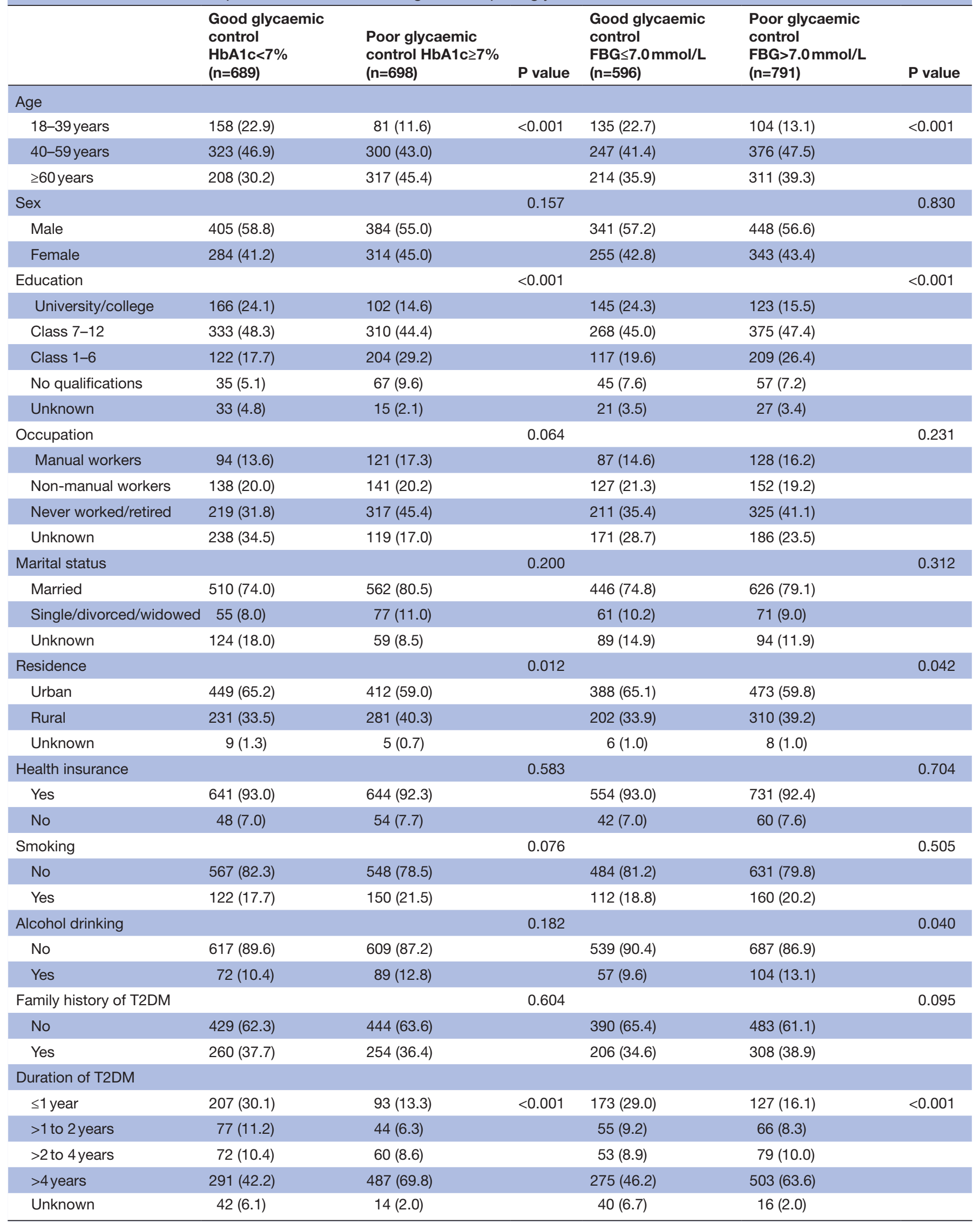


Table 1 Continued

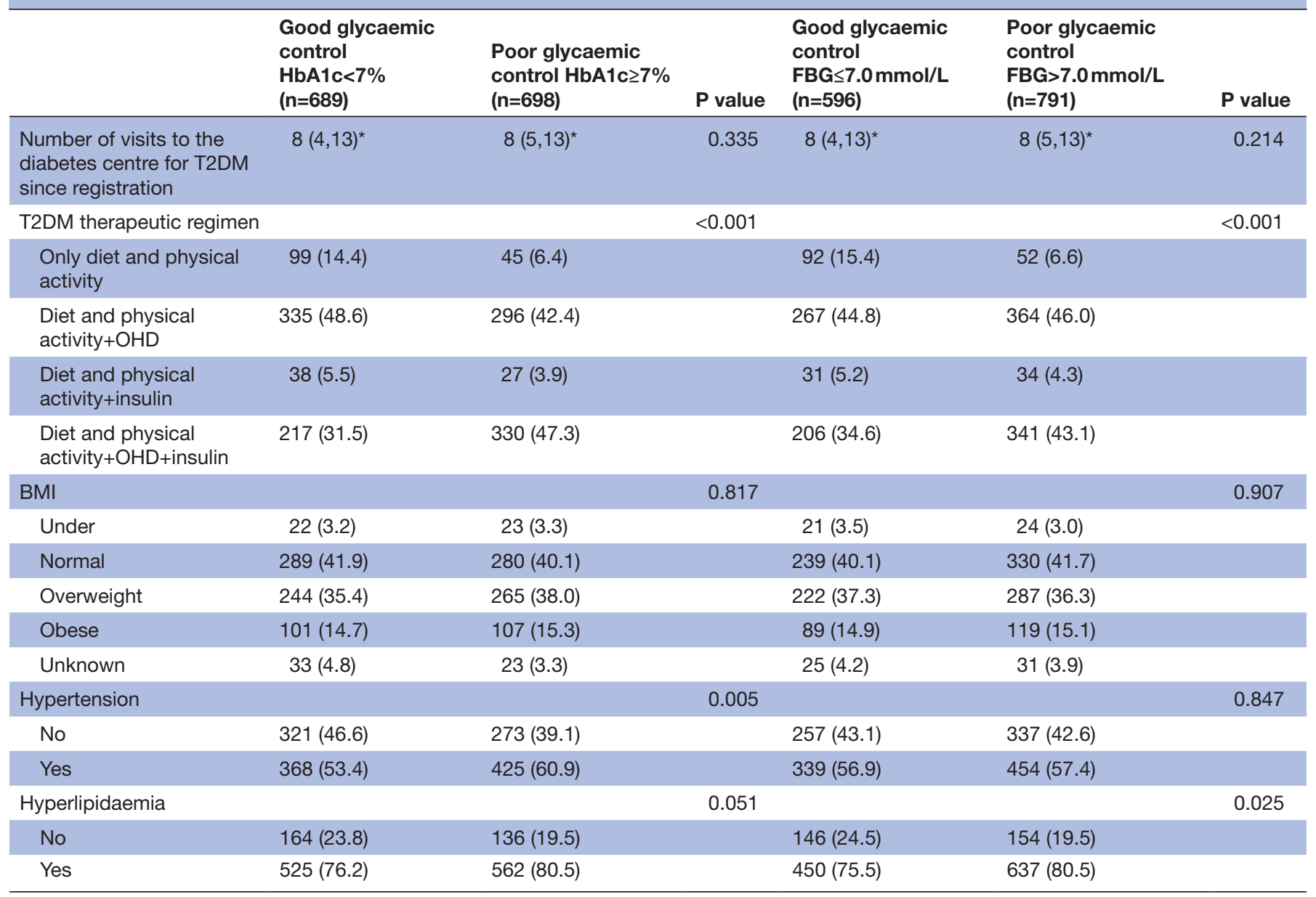

$\mathrm{n}(\%), \mathrm{p}$ value excludes unknown.

*Median (IQR).

BMI, body mass index; FBG, fasting blood glucose; HbA1c, glycated haemoglobin; OHD, oral hypoglycaemic drug; T2DM, type 2 diabetes mellitus.

should be explored and be taken into consideration in future studies.

The 'hukou' system was used to classify patients with T2DM into urban or rural residents. An association was found between poor glycaemic control and rural residents, which indicates health inequalities in T2DM management. This finding is consistent with another recently conducted study in China. ${ }^{5}$ In addition to poor socioeconomic conditions of rural residents in China, no or delayed access to healthcare is a major issue in rural areas. ${ }^{34}$ Even the health insurance system is different in rural and urban areas. ${ }^{35-37}$ There are discrepancies in resource allocation between rural and urban areas. All these could explain the association found between poor glycaemic control and rural residents.

Like T2DM, hyperlipidaemia is a risk factor for cardiovascular disease. ${ }^{38}$ The association found between poor glycaemic control and hyperlipidaemia is consistent with previous studies. ${ }^{26}{ }^{39}$ Glycaemic control mainly depends on the degree of residual pancreatic $\beta$-cells function and insulin sensitivity. ${ }^{40}{ }^{41}$ It should be noted that in Chinese patients with T2DM, the defects in $\beta$-cells function are more pronounced than decreased insulin sensitivity. ${ }^{43}$ Abnormalities in lipid metabolism, characterised by an increase in serum lipids (total cholesterol and triglycerides), may result in lipid spill over to non-adipose tissues, such as pancreatic $\beta$-cells. This may lead to cellular dysfunction and lipoapoptosis. ${ }^{45}{ }^{45}$ It is also accepted that high serum triglyceride level is associated with insulin resistance. ${ }^{46}$ These mechanisms may partly explain the association found between poor glycaemic control and hyperlipidaemia. Further research needs to be conducted to confirm the role of hyperlipidaemia in long-term glycaemic control. In continuation, early initiation of lipid-lowing therapy in patients with T2DM may reduce the risk for cardiovascular disease.

The study has a number of strengths and weaknesses. This is the first study to explore glycaemic control in patients with T2DM at the tertiary care diabetes centre in Ningbo, China. In addition, as far as we are aware, this is the first study on this issue in the Zhejiang province of China. HbAlc and FBG were used to determine glycaemic control, which in turn provided a complete picture. HbA1c reflects the average blood glucose level 
Table 2 Logistic regression analyses to determine factors independently associated with poor glycaemic control

\begin{tabular}{|c|c|c|}
\hline & OR $(95 \% \mathrm{Cl})$ & $P$ value \\
\hline \multicolumn{3}{|l|}{$\mathrm{HbA} 1 \mathrm{c} \geq 7 \%$} \\
\hline Residence & & $<0.001$ \\
\hline Urban & 1 & \\
\hline Rural & 1.68 (1.24 to 2.28$)$ & \\
\hline Duration of T2DM & & $<0.001$ \\
\hline$\leq 1$ year & 1 & \\
\hline$>1$ to 2 years & 1.84 (1.06 to 3.19$)$ & \\
\hline$>2$ to 4 years & 3.32 (1.88 to 5.85$)$ & \\
\hline$>4$ years & 5.98 (4.09 to 8.75$)$ & \\
\hline Marital status & & 0.098 \\
\hline Married & 1 & \\
\hline Single/divorced/widowed & 1.45 (0.93 to 2.25$)$ & \\
\hline T2DM therapeutic regimen & & 0.001 \\
\hline Only diet and physical activity & 1 & \\
\hline Diet and physical activity+OHD & 1.80 (1.01 to 3.23$)$ & \\
\hline Diet and physical activity+insulin & 1.00 (0.43 to 2.33$)$ & \\
\hline $\begin{array}{l}\text { Diet and physical } \\
\text { activity+OHD+insulin }\end{array}$ & 2.47 (1.38 to 4.41$)$ & \\
\hline Hyperlipidaemia & & 0.008 \\
\hline No & 1 & \\
\hline Yes & 1.57 (1.12 to 2.19$)$ & \\
\hline \multicolumn{3}{|l|}{$\mathrm{FBG}>7 \mathrm{mmol} / \mathrm{L}$} \\
\hline Residence & & 0.019 \\
\hline Urban & 1 & \\
\hline Rural & $1.42(1.06$ to 1.91$)$ & \\
\hline Duration of T2DM & & $<0.001$ \\
\hline$\leq 1$ year & 1 & \\
\hline$>1$ to 2 years & 2.10 (1.22 to 3.62$)$ & \\
\hline$>2$ to 4 years & 2.48 (1.42 to 4.34$)$ & \\
\hline$>4$ years & 3.34 (2.32 to 4.80$)$ & \\
\hline T2DM therapeutic regimen & & 0.005 \\
\hline Only diet and physical activity & 1 & \\
\hline Diet and physical activity+OHD & 2.40 (1.36 to 4.26$)$ & \\
\hline Diet and physical activity+insulin & 2.02 (0.88 to 4.62$)$ & \\
\hline $\begin{array}{l}\text { Diet and physical } \\
\text { activity+OHD+insulin }\end{array}$ & 2.78 (1.58 to 4.92$)$ & \\
\hline Hyperlipidaemia & & 0.002 \\
\hline No & 1 & \\
\hline Yes & 1.68 (1.21 to 2.33$)$ & \\
\hline Hypertension & & 0.045 \\
\hline No & 1 & \\
\hline Yes & 0.73 (0.54 to 0.99$)$ & \\
\hline
\end{tabular}

FBG, fasting blood glucose; HbA1c, glycated haemoglobin; OHD, oral hypoglycaemic drug; T2DM, type 2 diabetes mellitus.

over the past 3 months. On the other hand, FBG is a shortterm index. In terms of generalisability, the study findings could be valid in settings with similar populations and healthcare systems. Missing data could lead to bias but were generally low in this study. Multiple regression
Table 3 Sensitivity analyses: multiple logistic regression models included those variables with $p \leq 0.20$ in simple logistic regressions

\begin{tabular}{|c|c|c|}
\hline & OR $(95 \% \mathrm{Cl})$ & $P$ value \\
\hline \multicolumn{3}{|l|}{$\mathrm{HbA} 1 \mathrm{c} \geq 7 \%$} \\
\hline Residence & & $<0.001$ \\
\hline Urban & 1 & \\
\hline Rural & 1.68 (1.24 to 2.29$)$ & \\
\hline Duration of T2DM & & $<0.001$ \\
\hline$\leq 1$ year & 1 & \\
\hline$>1$ to 2 years & 1.83 (1.05 to 3.18$)$ & \\
\hline$>2$ to 4 years & 3.29 (1.88 to 5.77$)$ & \\
\hline$>4$ years & 5.99 (4.09 to 8.76$)$ & \\
\hline Marital status & & 0.096 \\
\hline Married & 1 & \\
\hline Single/divorced/widowed & 1.45 (0.94 to 2.25$)$ & \\
\hline T2DM therapeutic regimen & & $<0.001$ \\
\hline Only diet and physical activity & 1 & \\
\hline Diet and physical activity+OHD & 1.93 (1.08 to 3.45$)$ & \\
\hline $\begin{array}{l}\text { Diet and physical } \\
\text { activity+insulin }\end{array}$ & 1.03 (0.45 to 2.39$)$ & \\
\hline $\begin{array}{l}\text { Diet and physical } \\
\text { activity+OHD+insulin }\end{array}$ & 2.65 (1.49 to 4.72$)$ & \\
\hline Hyperlipidaemia & & 0.007 \\
\hline No & 1 & \\
\hline Yes & 1.58 (1.13 to 2.20$)$ & \\
\hline \multicolumn{3}{|l|}{$\mathrm{FBG}>7 \mathrm{mmol} / \mathrm{L}$} \\
\hline Residence & & 0.044 \\
\hline Urban & 1 & \\
\hline Rural & 1.28 (1.01 to 1.62$)$ & \\
\hline Duration of T2DM & & $<0.001$ \\
\hline$\leq 1$ year & 1 & \\
\hline$>1$ to 2 years & 1.67 (1.08 to 2.60$)$ & \\
\hline$>2$ to 4 years & 2.16 (1.40 to 3.33$)$ & \\
\hline$>4$ years & 2.51 (1.89 to 3.32$)$ & \\
\hline T2DM therapeutic regimen & & 0.002 \\
\hline Only diet and physical activity & 1 & \\
\hline Diet and physical activity+OHD & 1.90 (1.25 to 2.89$)$ & \\
\hline $\begin{array}{l}\text { Diet and physical } \\
\text { activity+insulin }\end{array}$ & $1.66(0.87$ to 3.19$)$ & \\
\hline $\begin{array}{l}\text { Diet and physical } \\
\text { activity+OHD+insulin }\end{array}$ & 2.30 (1.50 to 3.52$)$ & \\
\hline Hyperlipidaemia & & 0.020 \\
\hline No & 1 & \\
\hline Yes & 1.39 (1.05 to 1.83$)$ & \\
\hline
\end{tabular}

FBG, fasting blood glucose; HbA1c, glycated haemoglobin; OHD, oral hypoglycaemic drug; T2DM, type 2 diabetes mellitus.

analyses included a sample with missing values for the adjusted variables. This retrospective study was conducted using an existing database, which is primarily developed for the clinical purpose and not for research. It is possible that our findings were the result of other factors not 
present in the database and thus, not adjusted for in the models, such as self-monitoring of blood glucose, uptake and adherence to the T2DM therapeutic regimen and depression, anxiety and stress levels of patients. ${ }^{25} 4748$ Although the data were available on time, however, the other data quality issues of routinely collected data cannot be ignored, such as accuracy and reliability. Some of the data were self-reported (eg, duration of T2DM), and recall error could have been a problem. This inaccurate measurement of the variable could mean that individuals were assigned to the wrong category and then resulted in an incorrect estimation of the association between duration of T2DM and poor glycaemic control. As this was a cross-sectional study, it was not possible to determine the causal association between different variables and glycaemic control. A long-term, longitudinal study should be conducted among these patients to assess the impact of various factors (these as well as other potential factors) on their glycaemic control. Ours was a hospital-based study and a population-based study should be conducted, which might give a different picture. This could be because of different population characteristics, including their healthcare-seeking behaviour.

In conclusion, more than half of patients with T2DM at the diabetes centre in Ningbo, China have poor glycaemic control, and the predictors of glycaemic control were identified. The study findings could be taken into consideration in future interventional studies aimed at improving glycaemic control in these patients.

Acknowledgements The authors thank Yida Li (Yinal Software Corporation) for the management and organisation of original data and the patients.

Contributors $\mathrm{JL}$ and $\mathrm{KC}$ designed the study, analysed the data and wrote the first draft of the manuscript. JL, KC, MX, YC, FH, JC and LL revised it critically for important intellectual content and approved the final version.

Funding The study was supported by the Natural Science Foundation of Ningbo Municipality (CN) (Grant No. 2016A610169).

Competing interests None declared.

Patient consent Detail has been removed from this case description/these case descriptions to ensure anonymity. The editors and reviewers have seen the detailed information available and are satisfied that the information backs up the case the authors are making.

Ethics approval The study was ethically approved by the Research Ethics Committee at the Ningbo First Hospital, China.

Provenance and peer review Not commissioned; externally peer reviewed.

Data sharing statement The dataset will be available upon request unless there are legal or ethical reasons for not doing so.

Open Access This is an Open Access article distributed in accordance with the Creative Commons Attribution Non Commercial (CC BY-NC 4.0) license, which permits others to distribute, remix, adapt, build upon this work non-commercially, and license their derivative works on different terms, provided the original work is properly cited and the use is non-commercial. See: http://creativecommons.org/ licenses/by-nc/4.0/

(C) Article author(s) (or their employer(s) unless otherwise stated in the text of the article) 2018. All rights reserved. No commercial use is permitted unless otherwise expressly granted.

\section{REFERENCES}

1. International Diabetes Federation. IDF diabetes atlas. 8th edn. Brussels: Belgium, 2017.
2. World Health Organization. Global report on diabetes. Geneva, Switzerland: World Health Organization, 2016.

3. World Health Organization. Rate of diabetes in China "explosive". http://www.wpro.who.int/china/mediacentre/releases/2016/ 20160406/en/ (accessed 23 Aug 2017).

4. Cheng TO. Diabetes epidemic in China and its economic impact. Int $J$ Cardiol 2011;149:1-3.

5. Wang L, Gao P, Zhang M, et al. Prevalence and ethnic pattern of diabetes and prediabetes in China in 2013. JAMA 2017;317:2515-23.

6. Ji L, Hu D, Pan C, et al. Primacy of the 3B approach to control risk factors for cardiovascular disease in type 2 diabetes patients. Am J Med 2013;126:925.e11-22.

7. Liu L, Lou Q, Guo X, et al. Management status and its predictive factors in patients with type 2 diabetes in China: a nationwide multicenter study. Diabetes Metab Res Rev 2015;31:811-6.

8. Ji LN, Lu JM, Guo XH, et al. Glycemic control among patients in China with type 2 diabetes mellitus receiving oral drugs or injectables. BMC Public Health 2013;13:602.

9. $\mathrm{Xu} \mathrm{Y}, \mathrm{Wang} \mathrm{L}, \mathrm{He} \mathrm{J}$, et al. Prevalence and control of diabetes in Chinese adults. JAMA 2013;310:948-59.

10. Lipska KJ, Yao X, Herrin J, et al. Trends in drug utilization, glycemic control, and rates of severe hypoglycemia, 2006-2013. Diabetes Care 2017;40:468-75.

11. Cheung BM, Ong KL, Cherny SS, et al. Diabetes prevalence and therapeutic target achievement in the United States, 1999 to 2006. Am J Med 2009;122:443-53.

12. Ministry of Health of the People's Republic of China. The measures for the administration of the hospital grade, 1989.

13. Yao DZ, Sun XH, Jh L, et al. Prevalence and risk factors of diabetes in people over 40 years of age in Ningbo city area. Modern Practical Medicine 2016;28:1343-5.

14. The Public Health Service Platform of Ningbo. Ningbo first hospital. http://gzjk.nbws.gov.cn/f/mech?mechld=121 (accessed 14 Aug 2017).

15. The National People's Congress of the People's Republic of China. Regulations of the People's Republic of China on Residence Registration. http://www.npc.gov.cn/wxzl/gongbao/2000-12/10/ content_5004332.htm (accessed 23 Aug 2017).

16. Chinese Diabetes Society. China guideline for type 2 diabetes (2013 ed). Chin J Endocrinol Metab 2014;30:893-942.

17. China Expert Panel of Medical Nutrition Therapy for Overweight/ Obesity. Expert consensus on medical nutrition therapy for overweight/obesity in China. Chin J Diabetes Mellitus 2016;9:525-40.

18. Ningbo Municipal Human Resources and Social Security Bureau. Catalogue of drugs for basic medical insurance. http://www.zjnb.Iss. gov.cn/cx/cxzx/ybxx/ybyp/ypmu/\#Menu=1312 (accessed on 23 Aug 2017).

19. Bi Y, Zhu D, Cheng J, et al. The status of glycemic control: a crosssectional study of outpatients with type 2 diabetes mellitus across primary, secondary, and tertiary hospitals in the Jiangsu province of China. Clin Ther 2010;32:973-83.

20. Chiu M, Austin PC, Manuel DG, et al. Deriving ethnic-specific BMI cutoff points for assessing diabetes risk. Diabetes Care $2011 ; 34: 1741-8$

21. Chan JC, Gagliardino JJ, Baik SH, et al. Multifaceted determinants for achieving glycemic control: the International Diabetes Management Practice Study (IDMPS). Diabetes Care 2009;32:227-33.

22. Shan S, Gu L, Lou Q, et al. Evaluation of glycemic control in patients with type 2 diabetes mellitus in Chinese communities: a crosssectional study. Clin Exp Med 2017;17:79-84.

23. Shani M, Taylor TR, Vinker S, et al. Characteristics of diabetics with poor glycemic control who achieve good control. J Am Board Fam Med 2008;21:490-6.

24. Roy S, Sherman A, Monari-Sparks MJ, et al. Association of comorbid and metabolic factors with optimal control of type 2 diabetes mellitus. N Am J Med Sci 2016;8:31-9.

25. Kamuhabwa AR, Charles E. Predictors of poor glycemic control in type 2 diabetic patients attending public hospitals in Dar es Salaam. Drug Healthc Patient Saf 2014;6:155-65.

26. Sazlina SG, Mastura I, Cheong AT, et al. Predictors of poor glycaemic control in older patients with type 2 diabetes mellitus. Singapore Med J 2015;56:284-90.

27. Li MZ, Ji LN, Meng ZL, et al. Management status of type 2 diabetes mellitus in tertiary hospitals in Beijing: gap between guideline and reality. Chin Med J 2012;125:4185-9.

28. Khattab M, Khader YS, Al-Khawaldeh A, et al. Factors associated with poor glycemic control among patients with type 2 diabetes. $J$ Diabetes Complications 2010;24:84-9. 
29. U.K. prospective diabetes study 16. Overview of 6 years' therapy of type II diabetes: a progressive disease. U.K. Prospective Diabetes Study Group. Diabetes 1995;44:1249-58

30. Chiu CJ, Wray LA. Factors predicting glycemic control in middleaged and older adults with type 2 diabetes. Prev Chronic Dis 2010;7:A08.

31. Ji L, Zhang P, Weng J, et al. Observational Registry of Basal Insulin Treatment (ORBIT) in patients with type 2 diabetes uncontrolled by oral hypoglycemic agents in China: study design and baseline characteristics. Diabetes Technol Ther 2015;17:735-44.

32. Ross SA. Breaking down patient and physician barriers to optimize glycemic control in type 2 diabetes. Am J Med 2013;126:S38-S48.

33. Le C, Rong S, Dingyun Y, et al. Socioeconomic disparities in type 2 diabetes mellitus prevalence and self-management behaviors in rural southwest China. Diabetes Res Clin Pract 2016;121:9-16.

34. Syed ST, Gerber BS, Sharp LK. Traveling towards disease: transportation barriers to health care access. J Community Health 2013;38:976-93.

35. Yip WC, Hsiao WC, Chen W, et al. Early appraisal of China's huge and complex health-care reforms. Lancet 2012;379:833-42.

36. Dong K. Medical insurance system evolution in China. China Economic Review 2009;20:591-7.

37. Liu X, Wong H, Liu K. Outcome-based health equity across different social health insurance schemes for the elderly in China. BMC Health Serv Res 2016;16:9.

38. Nelson $\mathrm{RH}$. Hyperlipidemia as a risk factor for cardiovascular disease. Prim Care 2013;40:195-211.

39. Zhang SL, Chen ZC, Yan L, et al. Determinants for inadequate glycaemic control in Chinese patients with mild-to-moderate type 2 diabetes on oral antidiabetic drugs alone. Chin Med J 2011;124:2461-8.

40. Dansuntornwong B, Chanprasertyothin S, Jongjaroenprasert W, et al. The relation between parameters from homeostasis model assessment and glycemic control in type 2 diabetes. J Med Assoc Thai 2007;90:2284-90.

41. TODAY Study Group. Effects of metformin, metformin plus rosiglitazone, and metformin plus lifestyle on insulin sensitivity and $\beta$-cell function in TODAY. Diabetes Care 2013;36:1749-57.

42. China Insulin Secretion Study Group. Features of insulin secretion and insulin resistance in Chinese newly-diagnosed type 2 diabetes. Chin J Endocrinol Metab 2008;24:256-60.

43. Xiao J, Weng J, Ji L, et al. Worse pancreatic $\beta$-cell function and better insulin sensitivity in older Chinese without diabetes. J Gerontol A Biol Sci Med Sci 2014;69:463-70.

44. Kusminski CM, Shetty S, Orci L, et al. Diabetes and apoptosis: lipotoxicity. Apoptosis 2009;14:1484-95.

45. Irace C, Tripolino C, Carallo C, et al. Clinical predictors of progressive beta-cell failure in type 2 diabetes. J Investig Med 2015;63:802-5.

46. Li N, Fu J, Koonen DP, et al. Are hypertriglyceridemia and low HDL causal factors in the development of insulin resistance? Atherosclerosis 2014;233:130-8.

47. Gorska-Ciebiada M, Ciebiada M. Predictors of poor glycaemic control in type 2 diabetic elderly patients with depressive syndrome. Psychogeriatrics 2017;17:504-5.

48. Anderson RJ, Grigsby AB, Freedland KE, et al. Anxiety and poor glycemic control: a meta-analytic review of the literature. Int $J$ Psychiatry Med 2002;32:235-47. 